\title{
Parotid Sparing Study in Head and Neck Cancer Patients Receiving Bilateral Radiation Therapy: One-year Results
}

\author{
J.A. Ship ${ }^{1 *}$, A. Eisbruch ${ }^{2}$, E. D'Hondt ${ }^{1}$, and R.E. Jones ${ }^{1,3}$ \\ 'Department of Oral Medicine, Pathology, Surgery, University of Michigan School of Dentistry, 1011 N. University, Room 2010, Ann Arbor, \\ Michigan 48109-1078; ${ }^{2}$ Department of Radiation Oncology, University of Michigan Medical Center, Ann Arbor, Michigan; and ${ }^{3}$ Odessa \\ Brown Children's Clinic, Seattle, WA; *to whom correspondence should be addressed
}

\begin{abstract}
Many patients with head and neck cancers receive radiation therapy as part of their treatment which frequently causes considerable morbidity, including various degrees of permanent salivary gland dysfunction. Threedimensional treatment planning [3-DTP] and conformational dose delivery constitute a new therapeutic modality that conforms the high-dose radiation volume to the shape of the tumor volume while minimizing the dose to tissue that is not at risk of containing cancer. The treatment volumes for head and neck tumors as well as parotid glands can be well-defined on cross-sectional CT imaging techniques. The purpose of this investigation is to determine if 3-DTP and conformational dose-delivery could minimize radiation dose and salivary gland dysfunction to contralateral parotid glands in patients with head and neck cancers. Eleven patients with head and neck cancers who required bilateral radiation therapy were treated with 3 DTP. Unstimulated and stimulated bilateral parotid saliva was collected prior to radiotherapy, weekly during treatment, and 1,3,6, and 12 months after the completion of radiotherapy. Treated parotid glands received an average dose of 5745 cGy, while spared glands received only 1986 cGy $(p<0.0001)$. Unstimulated and stimulated parotid flow rates decreased dramatically in treated glands after the initiation of radiotherapy, remained at extremely low rates without any improvements, and were significantly lower at 1 year after radiotherapy compared with baseline. Conversely, parotid flow rates in spared glands underwent mild changes during radiotherapy and were approximately $50 \%$ of baseline values. The results of this study suggest that with the use of 3-DTP, contralateral parotid gland function can be partially preserved for at least 1 year in patients with head and neck cancers requiring bilateral radiation.
\end{abstract}

Key words: salivary gland function, three-dimensional treatment planning, parotid sparing, head and neck cancer.

Received June 11, 1996; Accepted October 30, 1996

\section{Introduction}

In 1995 , there were an estimated 28,150 newly reported cases of oral-pharyngeal cancer in the United States, resulting in over 8370 deaths from these cancers (Wingo et al., 1995). Many of these patients receive radiation therapy as part of their treatment. The goal of radiation therapy is to eradicate the tumor without causing significant or permanent damage to the oral-pharyngeal tissues that are at low risk for cancer spread (Semba et al., 1994). Currently, many of the radiation therapy techniques used in the treatment of head and neck cancer have serious side-effects detrimental to the oral cavity, including the loss of salivary gland function and a persistent complaint of a dry mouth (xerostomia) (Valdez et al., 1993). Salivary secretions contain numerous proteins and electrolytes that provide dental remineralization, antimicrobial action, lubrication, buffering, and mucosal repair (Mandel, 1989). Patients with radiation-induced salivary dysfunction suffer from oral discomfort and mucositis, difficultly in chewing and swallowing, taste changes, dental caries, oral microbial changes, chronic esophagitis, and a diminished quality of life (Parsons, 1994; Whelton, 1996). Despite much research, there is still no effective treatment for radiation-induced salivary dysfunction (Greenspan, 1990).

Parotid glands consist entirely of serous acini, submandibular and sublingual glands contain mucous and serous acini, and minor salivary glands contain predominantly mucous acini (Young and Van Lennep, 1979). Serous acini are thought to be the most radiosensitive, followed by mucous cells and duct cells (Stephens et al., 1986). Data from rhesus monkey salivary glands (Stephens et al., 1991) suggest that irradiated serous cells undergo interphase cell death by a process of active cellular self-destruction (apoptosis).

Previous studies of head and neck radiotherapy patients have shown that there is a dose-response relationship in parotid flow rates (Valdez et al., 1993; Mira et al., 1981; Marks et al., 1981). For most head and neck cancers, radiation dosages delivered to tumor regions are greater than 4500 cGy (Parsons, 1994). Doses of from 2100 to 4000 cGy have been shown to cause significant damage to 
salivary glands (Mira et al., 1981).

Three-dimensional treatment planning [3-DTP] and conformational dose delivery constitute a new therapeutic modality that conforms the high-dose radiation volume to the shape of the tumor volume while minimizing the dose to tissue that is not at risk of containing cancer. Treatment volumes for head and neck tumors as well as parotid glands can be well-defined on cross-sectional CT imaging techniques. Beam's-eye-view displays are used to ensure adequate target volume coverage while excluding the opposite (contralateral) parotid gland from the primary beam. Recent results from our laboratory demonstrate that, by means of 3-DTP and dose delivery techniques, contralateral parotid gland function can be spared in patients with unilateral head and neck cancers 1 yr after radiation therapy (Jones et al., 1996). However, many patients with head and neck cancers require bilateral head and neck radiation due to extension of the cancer into the ipsilateral or bilateral lymph nodes. Usually these patients receive high-dose bilateral radiation, causing complete destruction of salivary gland function due to irradiation of both parotid glands (Franzen et al., 1992; Marks et al., 1981; Dreizen et al., 1977).

The purpose of this investigation was to determine if 3DTP and dose delivery could minimize radiation dose and salivary gland dysfunction to contralateral parotid glands in patients with head and neck cancers requiring bilateral radiation treatment without leading to an increase in locoregional failure (cancer recurrence). It was hypothesized that objective measurements of parotid salivary flow rates would be greater in spared glands compared with irradiated glands due to the use of 3-DTP and conformational dosedelivery techniques.

\section{Materials and methods}

\section{Subjects}

Entrance criteria for patients included an histologically confirmed invasive cancer of the head and neck region. Patients had to demonstrate a need for irradiation to both sides of the neck due to: (1) a central tumor; (2) a lateralized tumor and ipsilateral neck node metastases where the contralateral node involvement was high; or (3) the condition where the contralateral neck was clinically negative but contained microscopic disease which was surgically resected. A Southwestern Oncology Group (SWOG) performance status of 0-2 (Karnofsky > 40) was required for entrance into the study (Mor et al., 1984). Patients who had previous surgery on the contralateral parotid were ineligible, but those who had cancer surgery on the ipsilateral gland prior to radiotherapy were eligible. A signed informed consent form was also required. The experimental protocol and the consent form were approved by the University of Michigan IRB.

\section{3-D radiation treatment planning}

All patients underwent immobilization and full 3-DTP through the University of Michigan Radiation-Oncology planning system (Hazuka et al., 1993). The target volume included the primary tumor mass and lymph node areas which contained metastases along with adjacent areas that were at low risk for microscopic extension. Lymph node areas which were at risk for subclinical disease were defined and included in the target volume. For planning, the target volume was expanded by approximately $1 \mathrm{~cm}$ to account for uncertainties of the target location and set-up error. Both parotid glands were contoured into the planning system.

The goal of treatment planning was full exclusion of the contralateral parotid gland (in the case of a lateralized tumor) or the gland at the side of the neck least involved with the tumor (in the case of bilateral neck involvement) from the primary beam, with adequate volume coverage provided to the tumor area. If this was not possible, the treatment planning permitted the lowest dose possible to be administered to the contralateral gland or the side of the neck least involved. Frequently, the tail of the contralateral parotid gland was irradiated to provide complete coverage to contralateral subdigastric and jugular neck nodes. All patients were treated with continuous conventional fractionation, and received $1.8 \mathrm{~Gy}$ to $2.0 \mathrm{~Gy}$ fractions, 1 fraction per day, 5 fractions per week. All treatment was delivered with megavoltage energies by the linear acceleration or racetrack microtron.

\section{Parotid salivary flow measurements}

Bilateral parotid saliva was collected prior to radiation treatment (baseline), weekly during treatment, and at 1, 3,6, and 12 months after completion of radiotherapy. Subjects were instructed to refrain from eating, drinking, smoking, and oral hygiene for a minimum of $90 \mathrm{~min}$ prior to salivary collection. All patients were seen between $8 \mathrm{a} . \mathrm{m}$. and Noon to control for circadian variations in salivary gland function (Dawes, 1974). Unstimulated parotid saliva was collected from both parotid gland orifices (Stenson's duct) with the use of a CarlsonCrittenden cup as described previously (Baum, 1981; Heft and Baum, 1984). Salivary flow was stimulated by $2 \%$ citric acid swabbed onto the dorso-lateral surfaces of the tongue at 30second intervals for $2 \mathrm{~min}$ for equilibration. This was followed by a two-minute collection period during which gustatory stimulation was maintained (Tylenda et al., 1988). Following salivary collection, the volumes of all salivas were determined gravimetrically by means of an analytical balance, assuming a specific gravity of 1.0 .

Saliva was collected by two investigators (JAS and REJ) who were calibrated for unstimulated and stimulated parotid salivary flow rates. Unstimulated and $2 \%$ citrate-stimulated parotid salivas were collected from eight unmedicated and healthy subjects by both investigators. Inter-examiner correlation coefficients were 0.924 for unstimulated parotid and 0.925 for stimulated parotid flow rates.

\section{Statistical analysis}

To control for inter-individual differences in flow rates (Ship et al., 1991), we converted each subject's flow rates at each visit into the percentage of unstimulated or stimulated flow rate at baseline. Paired tests were used for comparisons between 
unstimulated and stimulated flow rates and percentages of baseline flow rates between untreated and spared glands for each collection period. Comparisons were also performed for unstimulated and stimulated parotid flow rates and the percentages of baseline flow rates between baseline and one-year postcompletion of radiation therapy for the treated and spared glands. A paired $t$ test was used where mean values were assumed to have normal distribution, and a two-sample robust analysis was used where normality was not a plausible assumption (DuMouchel, 1987). Direct comparisons (paired $t$ tests) were used for the evaluation of differences in the amount of radiation delivered to the spared and treated glands. All data were analyzed with the RS/ 1 software package (BBN Software Products Corp., Cambridge, MA). A criterion of $p<0.05$ was accepted for significance in all statistical tests.

\section{Results}

This paper describes the results from 11 patients treated to date with the use of 3-DTP over the course of a 66-week period up to $1 \mathrm{yr}$ post-radiation. The subjects consisted of nine males and two females, aged $60.4 \pm 9.9$ years (mean \pm sd; range, 45 to 75 years). Each patient was diagnosed with a head and neck cancer (Table 1) and met all of the entrance criteria of the investigation. With the use of 3-DTP, patients received significantly ( $\mathrm{p}=0.0001$ ) greater radiation to the treated parotid gland compared with the spared gland (Table 2). On average, radiation exposure to spared glands was less than one-third of the total amount of radiation delivered to treated glands. During the one-year period in all 11 patients following radiation therapy, there were no cases of cancer recurrence in the regions spared of radiotherapy.

Statistical tests on flow rate values and on the percentages of baseline flow rates revealed similar results with identical trends. For example, unstimulated flow rates from the treated glands were lower at 12 months after radiotherapy compared with baseline flow rates $(p=0.002)$, and percentages of unstimulated baseline flow rates from treated glands were also lower at 12 months after radiotherapy compared with baseline $(\mathrm{p}=0.000)$. Therefore, only statistical results from salivary flow rates will be provided.

Unstimulated parotid salivary flow rates in both treated and spared glands throughout the period of radiotherapy and up to $1 \mathrm{yr}$ after the completion of treatment are illustrated in Fig. 1. Salivary flow rates decreased dramatically in treated glands after the initiation of radiotherapy, and were significantly lower at $1 \mathrm{yr}$ after radiotherapy compared with baseline ( $p=0.002$ ). Alternatively, flow rates in spared glands underwent milder changes during radiation therapy compared with treated glands, and were approximately $50 \%$ of baseline values at 1 yr after radiotherapy compared with baseline ( $\mathrm{p}=0.004)$. There were no significant differences in unstimulated salivary flow rates between treated and spared glands at baseline; however, at the completion of radiotherapy and at $1,3,6$, and 12 months after the completion of radiotherapy, these differences were highly significant (Table 3 ). Unstimulated flow rates from treated glands were undetectable $(0.000 \mathrm{~mL} / \mathrm{min}) 1 \mathrm{yr}$ after the completion of radiotherapy, compared with output from spared glands (Fig. 1, Table 3).

Stimulated parotid salivary flow rates for treated and spared glands are illustrated in Fig. 2. Flow rates decreased over time in treated glands, and were significantly lower 1 yr after the completion of radiotherapy, compared with baseline values ( $p=$ $0.04)$. Conversely, stimulated flow rates did not change as dramatically in spared glands, and were statistically indistinguishable compared with baseline at 1 yr after radiotherapy $(\mathrm{p}>0.05)$. Direct comparisons of the flow rates between treated and spared glands showed significant differences at most collection periods during radiation treatment and at all collection periods after the completion of radiotherapy, with the exception of baseline (Table 4).

Salivary flow rates were also converted into percentages of baseline flow rates to control for inter-individual differences. The results for percentages of baseline unstimulated (Fig. 3) and stimulated (Fig. 4) parotid flow rates revealed similar trends as absolute values. Treated unstimulated and stimulated flow rates dropped dramatically after the first week of radiation and remained close to $0 \%$ of baseline values. Alternatively, function from spared glands was evident throughout the course of treatment. At $1 \mathrm{yr}$ after the completion of radiotherapy, median flow rates were $67 \%$ and
Table 2. Radiation dose

\begin{tabular}{l|c|c|c}
\hline Radiation Dose $(c G y)$ & Spared Gland $(n=11)$ & Treated Gland $(n=11)$ & p-Value \\
\hline Mean \pm SD & $1986 \pm 713$ & $5745 \pm 472$ & 0.0001 \\
Range & $1300-3500$ & $4700-6700$ & \\
\hline
\end{tabular}




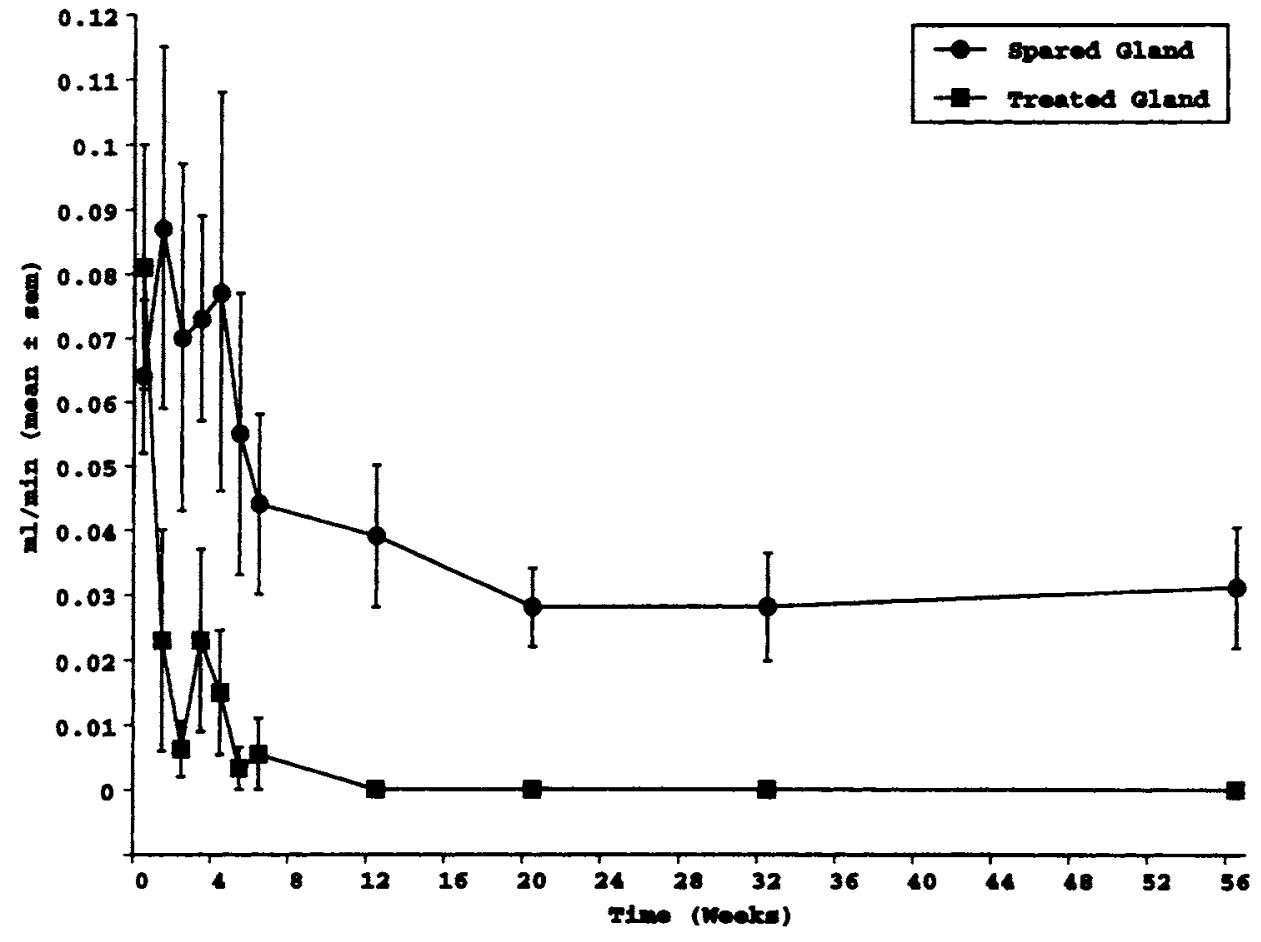

Figure 1. One-year data for unstimulated parotid salivary flow rates in treated and spared glands in 11 cancer patients receiving bilateral head and neck radiation. Flow rates were significantly lower in treated glands compared with spared glands at every visit except baseline.

$46 \%$ of baseline values, respectively, of baseline unstimulated and stimulated flow rates.

\section{Discussion}

Head and neck radiation therapy has a deleterious effect on salivary gland function (Dreizen et al., 1977; Marks et al., 1981; Mira et al., 1981; Larson et al., 1983; Stephens et al., 1986, 1991; Greenspan, 1990; Hazuka et al., 1993; Valdez et al., 1993; Parsons, 1994; Semba et al., 1994; Jones et al., 1996). There is a dose-dependent relationship between the amount of radiation delivered to oral tissues and the damage that eventually occurs (Marks et al., 1981; Mira et al., 1981; Valdez et al., 1993; Semba et al., 1994). It has also been documented that bilateral conventional radiotherapy causes greater oral discomfort and increased complaints of xerostomia compared with unilateral radiation therapy (Mira et al., 1981; Franzen et al., 1992).

Table 3. Average unstimulated flow rates ${ }^{a}$

\begin{tabular}{lccc}
\hline & Spared Gland $(\mathrm{n}=11)(\mathrm{mL} / \mathrm{min})$ & Treated Gland $(\mathrm{n}=11)(\mathrm{mL} / \mathrm{min})$ & $\mathrm{p}$ Value \\
\hline Baseline & $0.064 \pm 0.039$ & $0.081 \pm 0.063$ & $\mathrm{NS}^{\mathrm{b}}$ \\
Completion of radiation & $0.044 \pm 0.048$ & $0.006 \pm 0.018$ & 0.009 \\
3 months & $0.028 \pm 0.020$ & $0.000 \pm 0.000$ & 0.0009 \\
6 months & $0.028 \pm 0.026$ & $0.000 \pm 0.000$ & 0.008 \\
12 months & $0.031 \pm 0.031$ & $0.000 \pm 0.000$ & 0.008 \\
\hline
\end{tabular}

a Mean $\pm \mathrm{SD}$.

b NS = Not statistically significant.
Few long-term longitudinal studies have examined salivary function after completion of radiotherapy. Several studies reported permanent salivary dysfunction which was not reversible with time (Dreizen et al., 1977; Mira et al., 1981; Mossman et al., 1982). Conversely, several studies demonstrated partial salivary function recovery which was dependent on radiation dose, field of treatment, and length of follow-up after the completion of therapy (Eneroth et al., 1972; Franzen et al., 1992).

Using conventional bilateral radiation techniques, Dreizen $e t$ al. (1977) treated 26 patients with a minimum dose of $5000 \mathrm{cGy}$, and all patients showed a progressive loss of salivary function during and after treatment. Compared with baseline values, mean whole stimulated flow rates were $67 \%$ lower at the end of radiation therapy, $89 \%$ lower 1 yr post-radiation, and continued to decrease 3 yrs post-radiation (Dreizen et al, 1977). Dreizen $e t$ al. (1977) concluded that radiation-induced salivary dysfunction was irreversible. Valdez et al. (1993) examined unstimulated and stimulated parotid salivary flow rates and demonstrated that patients in the lowest radiation dose quartile ( $<5000 \mathrm{cGy}$ ) had significantly greater salivary flow rates compared with those in the highest dose quartile $>6800$ cGy). This study and others suggest that if the amount of radiation to the contralateral parotid gland can be minimized, some salivary function can be spared.

The one-year results of the present study demonstrate that contralateral parotid gland function can be spared in patients requiring bilateral radiation for head and neck cancers if 3-DTP and dose-delivery techniques are used. Through the use of 3-DTP, beam's-eye-view displays were used to design beam and blocking arrangements that excluded the contralateral parotid gland (Hazuka et al., 1993).

Consequently, spared glands received an average radiation dose of only 1986 cGy, $65.4 \%$ lower than that received by treated glands. This permitted a partial preservation of contralateral parotid function to occur, while nearly all output was lost in 
treated glands. Complete preservation of contralateral parotid glands is not possible in all patients, since the tail of the contralateral parotid gland may be fully irradiated to treat subdigastric and jugular neck nodes.

Unstimulated parotid salivary secretions play a vital role in the maintenance of oral health (Mandel, 1989). Alterations in these unstimulated fluids can impair oral and systemic health, since they confer protection to the host all day and night. Spared parotid glands in the present study received $65.4 \%$ less radiation than treated glands, which allowed for at least partial preservation of unstimulated parotid flow rates 12 months after the completion of radiation treatment. While preservation of unstimulated function was not $100 \%$, the presence of some unstimulated function will allow for subsequent stimulation with mechanical, gustatory, and pharmacological agents (Greenspan, 1990; Johnson et al., 1993; LeVeque et al., 1993; Atkinson and $\mathrm{Wu}, 1994)$.

Stimulated salivary fluids reflect the functional capacity of the gland, and play a major role during mealtime for mastication and deglutition. The median parotid stimulated flow rates 12 months after completion of radiation treatment in spared glands were $64 \%$ lower than baseline values, compared with $100 \%$ lower in treated glands. When nonsparing bilateral parotid radiation techniques were used, Dreizen et al. (1977) demonstrated that mean whole stimulated saliva flow rates were $89 \%$ lower than baseline values 1 yr postirradiation, and that flow rates progressively decreased through 3 yrs postirradiation. Conversely, the results from the present study demonstrate that mean stimulated flow rates increased slightly up to 12 months after the completion

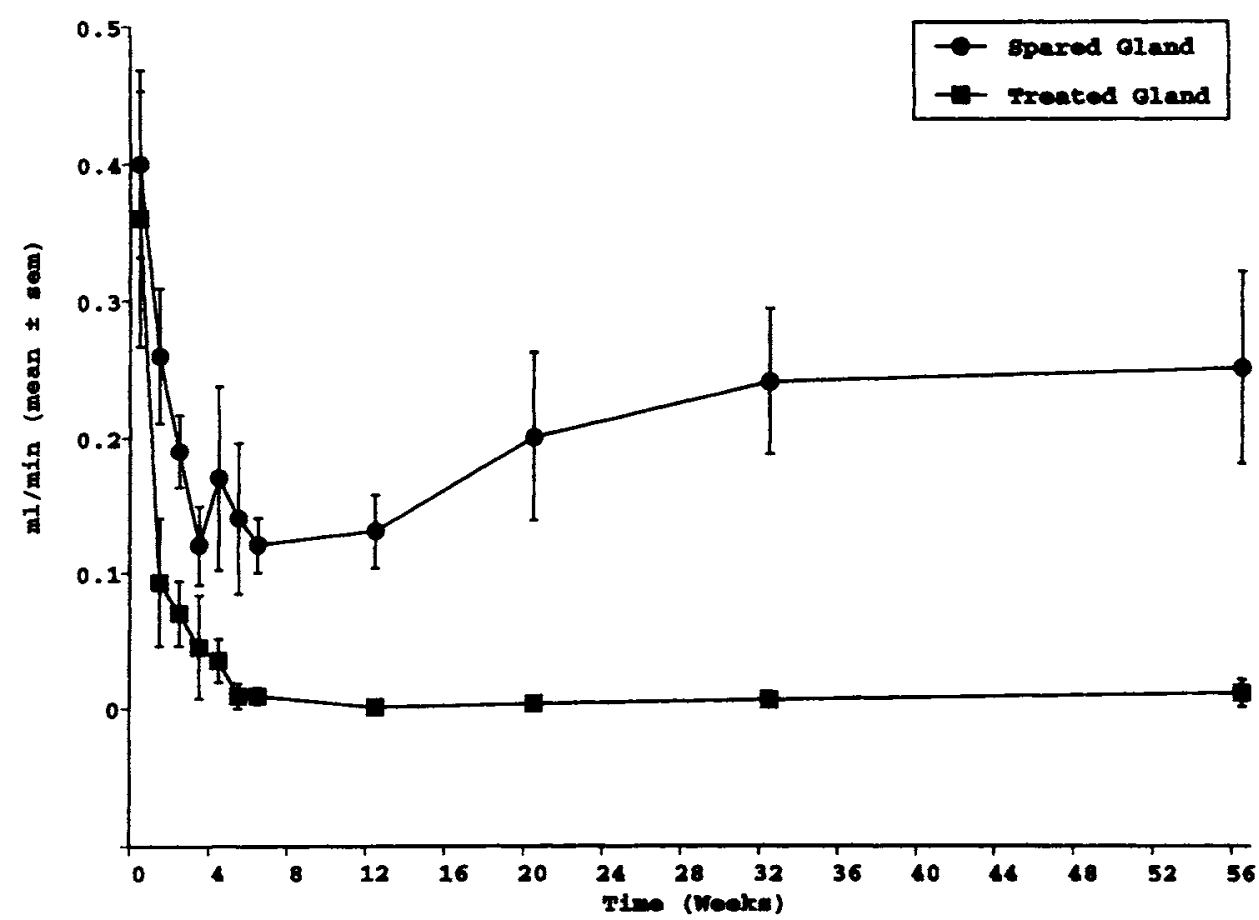

Figure 2. One-year data for stimulated parotid salivary flow rates in treated and spared glands in 11 cancer patients receiving bilateral head and neck radiation. Flow rates were significantly lower in treated glands compared with spared glands at every visit except baseline.

of radiation therapy (Table 4). Perhaps in some individuals, the radiation-induced loss of stimulated saliva function in spared glands may be partially reversible with time.

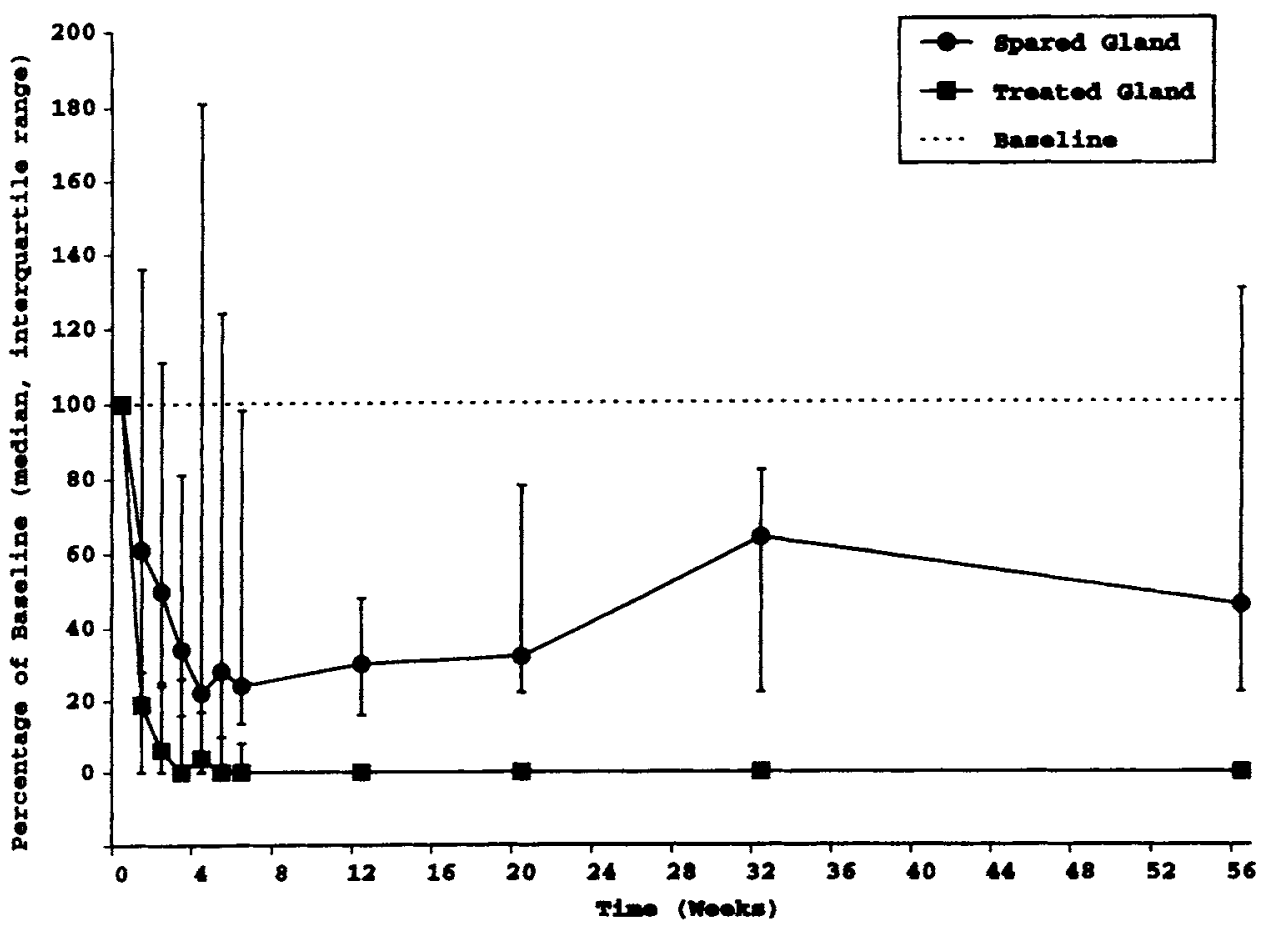

Figure 3. One-year data for percentages of baseline unstimulated parotid salivary flow rates in treated and spared glands in 11 cancer patients receiving bilateral head and neck radiation. Flow rates were significantly lower in treated glands compared with spared glands at every visit except baseline. 
Table 4. Average stimulated flow rates ${ }^{\mathrm{a}}$

\begin{tabular}{lccc}
\hline & Spared Gland $(\mathrm{n}=11)(\mathrm{mL} / \mathrm{min})$ & Treated Gland $(\mathrm{n}=11)(\mathrm{mL} / \mathrm{min})$ & $\mathrm{P}$ Value \\
\hline Baseline & $0.400 \pm 0.220$ & $0.360 \pm 0.310$ & $\mathrm{NS}^{\mathrm{b}}$ \\
Completion of radiation & $0.120 \pm 0.065$ & $0.008 \pm 0.020$ & 0.0004 \\
3 months & $0.200 \pm 0.210$ & $0.003 \pm 0.010$ & 0.05 \\
6 months & $0.240 \pm 0.170$ & $0.006 \pm 0.017$ & 0.001 \\
12 months & $0.250 \pm 0.023$ & $0.011 \pm 0.034$ & 0.006 \\
\hline
\end{tabular}

a $\quad$ Mean $\pm \mathrm{SD}$.

b NS = Not statistically significant.

There are some limitations to this study. First, this paper presents data on only 11 patients treated with bilateral 3-DTP up to 12 months after radiotherapy. Nevertheless, there are distinct and significant differences between spared and treated parotid glands. There are even slightly detectable trends of salivary gland recovery from spared glands with time. However, more patients are needed over a longer time period if we are to determine whether the trends observed are statistically significant in larger populations. Finally, subjective data on patients' xerostomia complaints are not included in this report. Responses to standardized xerostomia questions (Fox et al., 1987) have been collected, but due to the small sample size and large individual response variations, results to date have yielded no statistical significance.

The data from this study have some important clinical ramifications. Total loss of parotid salivary gland function may no longer be inevitable in patients with head and neck cancers who require bilateral radiation therapy. Parotid gland function can be partially preserved by 3DTP, resulting in a decrease in radiation-induced dysfunction. Consequently, the use of gustatory, masticatory, and pharmacological saliva stimulants as well as aggressive oral hygiene techniques can be used to help preserve oral health.

\section{Acknowledgments}

This study was funded by the University of Michigan School of Dentistry (Department of Oral Medicine/Pathology/Surgery) and the University of Michigan Medical Center (Department of Radiation Oncology and Department of Hospital Dentistry). The authors would like to thank the American Association for Dental Research for awarding Eric D'Hondt a Student Research Fellowship for this investigation.

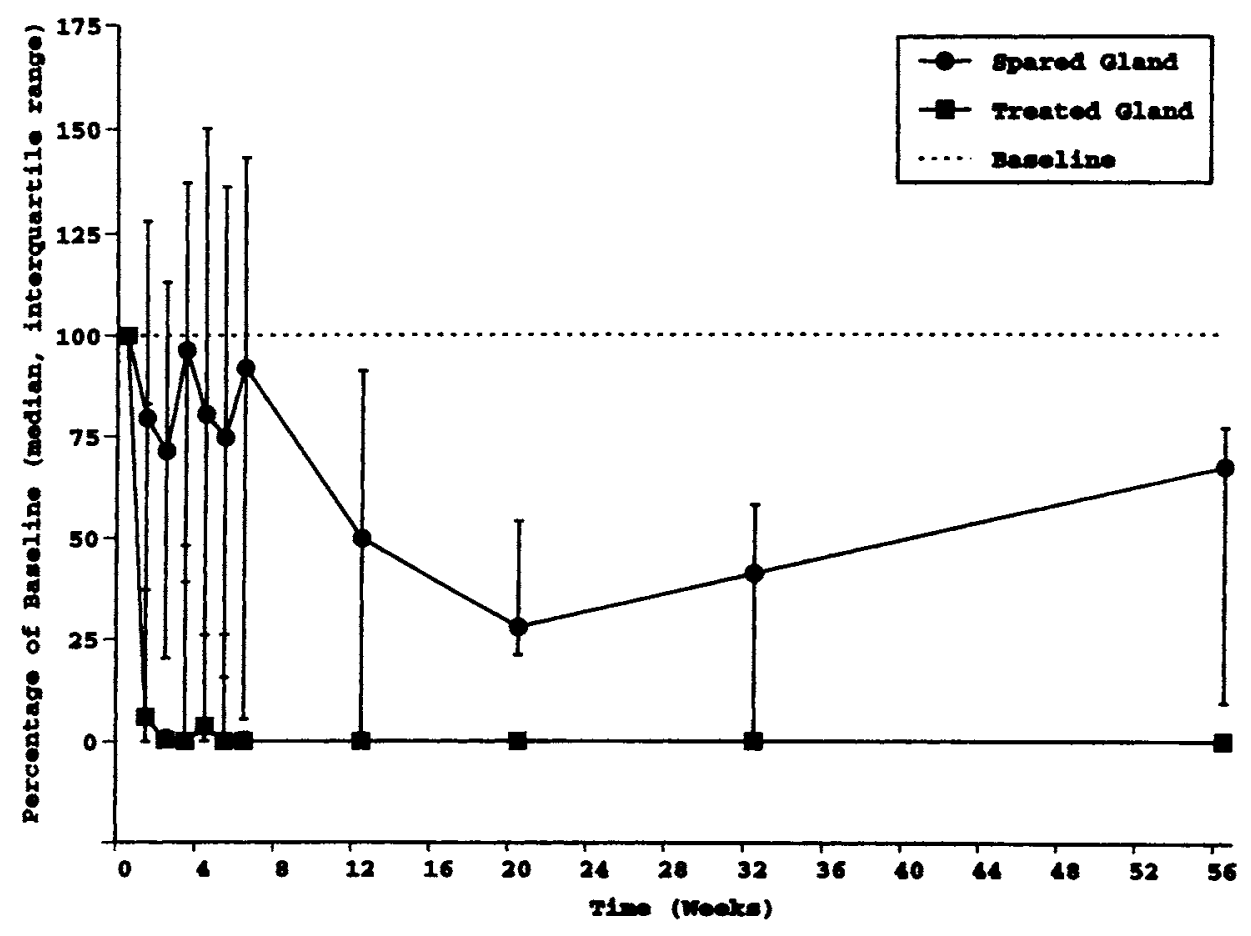

Figure 4. One-year data for percentages of baseline stimulated parotid salivary flow rates in treated and spared glands in 11 cancer patients receiving bilateral head and neck radiation. Flow rates were significantly lower in treated glands compared with spared glands at every visit except baseline.

\section{References}

American Joint Committee on Cancer (1988). Manual for staging of cancer. 3rd ed. Philadelphia: J.B. Lippincott.

Atkinson JC, Wu AJ (1994). Salivary gland dysfunction: Causes, symptoms, treatment. J Am Dent Assoc 125:409-416.

Baum BJ (1981). Evaluation of stimulated parotid saliva flow rates in different age groups. J Dent Res 60:1292-1296.

Dawes C (1974). Rhythms in salivary flow rate and composition. Int J Chronobiol 2:253-279.

Dreizen S, Brown LR, Daly TE, Drane JB (1977). Prevention of xerostomia related dental caries in irradiated cancer patients. J Dent Res 36:99-104.

DuMouchel W (1987). A data analysis advisor. Technical report. Cambridge, MA: BBN Software Products Corporation. 
Eneroth CM, Henrickson CO, Jakobsson PA (1972). Effect of fractionated radiotherapy on salivary gland function. Cancer 30:1147-1153.

Fox PC, Busch KA, Baum BJ (1987). Subjective reports on xerostomia and objective measurements of salivary gland performance. J Am Dent Assoc 115:581-584.

Franzen L, Funegard U, Ericson T, Henriksson R (1992). Parotid gland function during and following radiotherapy of malignancies in the head and neck: A consecutive study on salivary flow rates and patient discomfort. Eur $J$ Cancer 28:457-462.

Greenspan D (1990). Oral complications of cancer therapies. Management of salivary dysfunction. NCI Monographs 9:159-161.

Hazuka MB, Martel MK, Marsh L, Lichter AS, Wolf GT (1993). Preservation of parotid function after external beam irradiation in head and neck cancer patients: a feasibility study using 3-dimensional (3-D) treatment planning. Int $J$ Radiation Oncology Biol Phys 27:731-737.

Heft MW, Baum BJ (1984). Unstimulated and stimulated parotid salivary flow rate in individuals of different ages. I Dent Res 63:1182-1185.

Johnson JT, Ferretti GA, Nethery WJ, Valdez IH, Fox PC, Ng D, et al. (1993). Oral pilocarpine for post-irradiation xerostomia in patients with head and neck cancer. $N$ Engl $J$ Med 329:390-395.

Jones R, Takeuchi T, Eisbruch A, D'Hondt EG, Hazuka M, Ship JA (1996). Ipsilateral parotid sparing study in head and neck cancer patients receiving radiation therapy: 1 year results. Oral Surg Oral Med Oral Pathol Oral Radiol Endo 81:642-648.

Larson DL, Lindberg RD, Lane E, Goepfert H (1983). Major complications of radiotherapy in cancer of the oral cavity and oralpharynx. A 10 year retrospective study. Am J Surg 146:531-536.

LeVeque FG, Montgomery M, Potter D, Zimmer MB, Rieke JW, Steiger BW, et al. (1993). A multicenter, randomized, doubleblind, placebo-controlled, dose-titration study of oral pilocarpine for treatment of radiation-induced xerostomia in head and neck cancer patients. J Clin Oncol 6:1124-1131.

Mandel ID (1989). The role of saliva in maintaining oral homeostasis. J Am Dent Assoc 119:298-304.

Marks JE, Davis CC, Gottsman VL, Purdy JE, Lee F (1981). The effects of radiation on parotid salivary function. Int J Oncol Biol Phys 7:1013-1019.

Mira JG, Wescott WB, Starcke EN, Shannon IL (1981). Some factors influencing salivary function when treating with radiotherapy. Int J Radiat Oncol Biol Phys 7:535-541.

Mor V, Laliberte L, Morris JN, Wiemann M (1984). The Karnofsky Performance Status Scale: An examination of its reliability and validity in a research setting. Cancer 53:2002-2007.

Mossman K, Shatzman A, Chencharick J (1982). Long-term effects of radiotherapy on taste and salivary function in man. Int J Radiat Oncol Bio Phys 8:991-997.

Parsons JT (1994). Time-dose-volume relation in radiation therapy. In: Management of head and neck cancer. A multidisciplinary approach. Million RR, Cassisi NI, editors. Philadelphia, PA: Lippincott Co., pp. 173-243.

Semba SE, Mealey BL, Hallmon WW (1994). The head and neck radiotherapy patient: Part 1 -Oral manifestations of radiation therapy. Compend Contin Educ Dent 15:250-261.

Ship JA, Fox PC, Baum BJ (1991). How much saliva is enough? Normal function defined. I Am Dent Assoc 122:63-69.

Stephens LC, Ang KK, Schultheiss TE, King GK, Brock WA, Peters LJ (1986). Target cell and mode of radiation injury in rhesus salivary glands. Radiother Oncol 7:165-174.

Stephens LC, Schultheiss TE, Price RE, Ang KK, Peters LJ, et al. (1991). Radiation apoptosis of serous acinar cells of salivary and lacrimal glands. Cancer 67:1539-1543.

Tylenda CA, Ship JA, Fox PC, Baum BJ (1988). Evaluation of submandibular salivary flow rate in different age groups. $J$ Dent Res 67:1225-1228.

Valdez IH, Atkinson JC, Ship JA, Fox PC (1993). Major salivary gland function in patients with radiation-induced xerostomia: flow rates and sialochemistry. Int $J$ Radiation Oncol Biol Phys 25:41-47.

Whelton $H$ (1996). Introduction: The anatomy and physiology of salivary glands: In: Saliva and oral health. Edgar WM, O'Mullane DM, editors. London: British Dental Association, pp. 1-9.

Wingo PA, Tong T, Bolden S (1995). Cancer statistics, 1995. CA Cancer J Clin 45:8-30.

Young JA, Van Lennep EW (1979). Transport in salivary and salt glands. In: Membrane transport in biology. Giebisch $\mathrm{G}$, Tosteson DC, Ussing HH, editors. Berlin: Springer-Verlag, pp. 563-592. 